\title{
Samuel Beckett et la culture française, sous la direction de Y. MÉVEL
}

\section{Stefano Genetti}

\section{OpenEdition}

\section{Journals}

\section{Edizione digitale}

URL: https://journals.openedition.org/studifrancesi/44228

DOI: 10.4000/studifrancesi.44228

ISSN: 2421-5856

\section{Editore}

Rosenberg \& Sellier

\section{Edizione cartacea}

Data di pubblicazione: 1 juin 2021

Paginazione: $245-246$

ISSN: 0039-2944

Notizia bibliografica digitale

Stefano Genetti, «Samuel Beckett et la culture française, sous la direction de Y. MÉvEL», Studi Francesi

[Online], 193 (LXV | I) | 2021, online dal 01 juillet 2021, consultato il 15 octobre 2022. URL: http:// journals.openedition.org/studifrancesi/44228 ; DOI: https://doi.org/10.4000/studifrancesi.44228

Questo documento è stato generato automaticamente il 15 octobre 2022.

\section{@() $\Theta \Theta$}

Creative Commons - Attribuzione - Non commerciale - Non opere derivate 4.0 Internazionale - CC BY NC-ND 4.0

https://creativecommons.org/licenses/by-nc-nd/4.0/ 


\title{
Samuel Beckett et la culture française, sous la direction de Y. MÉVEL
}

\author{
Stefano Genetti
}

\section{NOTIZIA}

Samuel Beckett et la culture française, sous la direction de Y. MÉVEL, Paris, Lettres

Modernes Minard, 2019, 379 pp.

Disparati per argomento e per approccio, i saggi qui riuniti rendono conto del dialogo tra specialisti orientali e occidentali che ha contraddistinto un seminario francofono svoltosi in Giappone, dove gli studi su Beckett si sono sviluppati principalmente in inglese. Lo chiarisce il curatore del volume (corredato di indici dei nomi e delle opere) nell'Introduzione intitolata Beckett et la question des frontières nationales (pp. 15-36): a partire da una riflessione teorica sulla nozione di cultura declinata in termini linguistici, estetici, istituzionali e ideologici, Yann MÉvel fornisce un'efficace rassegna della letteratura sulla complessa appartenenza dell'opera beckettiana. Se, nella Note liminaire al volume (pp. 9-13), Llewellyn BRown constata l'attuale marginalizzazione della lingua francese sul piano internazionale e del dibattito intellettuale su quello nazionale, cui corrisponde, nell'ambito degli studi beckettiani, la marginalizzazione della critica francofona, è per sottolineare come quest'ultima sia caratterizzata da oggetti e strumenti di analisi specifici, atti a soppesare l'importanza della cultura francese in Beckett e quella di Beckett nella cultura francese, facendo dello scrittore irlandese "bilingue" un autore (anche) francese.

Da angolazioni diverse, si succedono trattazioni ad ampio raggio sull'adozione della lingua straniera come mezzo per mettere a distanza la propria storia personale e sull'autotraduzione come rinegoziazione dei rapporti con la lingua madre e la madre patria (Amanda DENNIS, Samuel Beckett et la langue maternelle. Ambivalence et expatriation linguistique, pp. 95-114); sul génie della lingua francese incarnato dai classici come antidoto contro ogni eccesso espressivo e come monito a relegare nell'indicibile le 
profondità della coscienza (Jean-Baptiste FROSSARD, Samuel Beckett e l'imaginaire de la clarté française, pp. 145-163); sul ricorso al monologo interiore (Stéphanie SMADJA, La "Trilogie" de Beckett dans l'histoire de la prose française, pp. 167-187); sulla centralità della voce e delle sensazioni uditive (Noriko taKayama, Poésie invisible et pensée cachée dans l'œuvre de Beckett, pp. 217-230); sulla vibrazione e la ripetizione seriale, l'intensità e l'estenuazione della materia sonora come principi compositivi, dalla "registrazione intransitiva" della Dernière bande fino a Souffle e ai drammi televisivi, considerati da François NOUDELMANN in qualità di dispositivi musicali (Écouter la musique de Samuel Beckett. "Chut!», pp. 329-339), mentre Yo fUjIWARA illustra come la concezione della musica del primo Beckett risenta del lessico proustiano almeno quanto dell'interpretazione metafisica mutata da Il mondo come volontà e rappresentazione ( $\mathrm{La}$ définition de la musique dans le "Proust" de Beckett, à travers sa lecture de Schopenhauer et de Proust, pp. 81-92). A questi contributi si affiancano paralleli puntuali - tra Molloy e Meursault, in chiave simbolica e psico-biografica (Izumi NISHIMURA, "Molloy" de Beckett et "L'étranger" de Camus à la recherche du maternel absent, pp. 189-213), oppure Beckett et Lévinas. L'espace et la respiration di Osamu Yoshino (pp. 231-253) - e letture di brani circoscritti. È così che Bruno CLÉMENT estende la propria analisi di un passo del romanzo Watt-l'allucinata, evanescente apparizione, accompagnata dal risuonare di poche parole, di una sagoma in lontananza - all'insieme dell'opera, rinvenendo nell'ipotiposi e nella prosopopea, che si fondono in un'unica «figure de l'imagination» (p. 326), i fondamenti della poetica di Beckett prosatore e drammaturgo (L'œil et l'oreille. Samuel Beckett et la question des figures, pp. 315-339).

3 Sulla formazione di Beckett, studente sotto la guida di Thomas Rudmose-Brown e poi insegnante presso il Trinity College di Dublino, si soffermano Angela MOORJANI (Beckett et la littérature française. Les années d'apprentissage, pp. 39-64) e Thomas HUNKELER (Beckett et la poésie française de Ronsard à Rimbaud. «Des mots qu'à l'air je jette», pp. 65-80). La prima, in base ai programmi di letteratura francese in vigore negli anni 1923-1926, mette in rilievo antipatie e predilezioni, individuando in Rabelais, Molière, Racine, Diderot, Stendhal, Flaubert e Baudelaire, oltre che in Proust e in Gide, alcuni degli autori che più lo hanno influenzato. Il secondo, distinguendo «la chasse aux phrases» (p. 69) del primo Beckett dalle allusioni intertestuali più tarde, evidenzia l'interesse del giovane francesista e traduttore, oltre che scrittore, per il patrimonio poetico, dalla lirica rinascimentale fino ad Apollinaire e a Éluard. In Beckett et la France, stratégies (de la liberté) d'appartenance. Le cas d'“Eleutheria" (pp. 115-143), Matthijs ENGELBERTS mostra come Beckett, rendendo omaggio a Vitrac e a Cocteau, inscriva la sua prima pièce, redatta all'inizio del 1947 e a lungo inedita, nell'avanguardia teatrale parigina al fine di emergere come auteur français, sancendo la liberazione da un contesto familiare e da una cultura nazionale percepiti come soffocanti.

4 Sulla ricezione dell'opera di Beckett vertono altri articoli. Nell'aggiornare la bibliografia degli studi di impianto psicanalitico, L. BRown sostiene che la critica francese si differenzia dalla French Theory anglo-americana per una maggiore sensibilità all'evoluzione del pensiero lacaniano, concorrendo a superare l'utilizzo in chiave strutturalista o decostruzionista di alcuni concetti chiave (Quel Lacan pour quel Beckett? Étude de la critique anglophone et française, pp. 255-291). Tra commento critico e rielaborazione creativa si colloca il ritratto che Martin MÉGEVAND delinea di Ludovic Janvier, studioso, co-traduttore di Watt e scrittore in proprio scomparso nel 2016. Tra gli ultimi ad aver frequentato l'autore, Janvier restituisce dell'opera di Beckett una 
visione plurale e dinamica, densa di implicazioni esistenziali, e del suo teatro una visione precocemente attenta alla componente performativa (Avec Ludovic Janvier. Au fil $d u$ théâtre beckettien, pp. 295-313). Sjef HoupPeRmans, infine, in Samuel Beckett et la littérature française d'aujourd'hui (pp. 341-356), misura l'impatto dell'eredità beckettiana sul panorama contemporaneo selezionando, da un lato, il teatro di Valère Novarina e in particolare il monologo di Adrémelech in Babil des classes dangereuses, dall'altro, la prosa inventiva e autoriflessiva di Éric Chevillard, il cui libro d'esordio, Mourir m'emrhume, si situa in continuità con Malone meurt di Beckett. Dell'ilarità, che rappresenta una dominante comune ai due autori, costituisce del resto un esempio l'irriverente racconto di Chevillard Les taupes, incluso in Scalps (Fata Morgana, 2004, pp. 37-47): "Quand j'étais enfant, nous habitions à côté de chez Samuel Beckett, à Ussy. Je m'amusais à lancer des taupes dans son jardin». 